\title{
Prevention of cardiac herniation and left artery descending obstruction in cases of extensive surgical pericardial window procedure
}

\author{
Anton Sabashnikov, Ferdinand Kuhn-Régnier, Mohamed Zeriouh, Yeong-Hoon Choi, Navid Madershahian, \\ Thorsten Wahlers \\ Department of Cardiothoracic Surgery, University Hospital of Cologne, Cologne, Germany \\ Correspondence to: Anton Sabashnikov, MD, PhD. Department of Cardiothoracic Surgery, University Hospital of Cologne, Kerpener Str. 62 , 50937 \\ Cologne, Germany. Email: a.sabashnikov@gmail.com.
}

\begin{abstract}
The thoracotomy approach for pericardial window surgery was shown to be more effective at preventing effusion recurrence and the need for repeat surgery. However, cardiac herniation remains a common complication after extensive pericardial excision. This technical note describes a simple and effective technique to prevent potential heart herniation through the pericardial window and at the same time to avoid potential obstruction of the left artery descending.
\end{abstract}

Keywords: Pericardial window; cardiac herniation; pericardial effusion

Submitted Mar 06, 2017. Accepted for publication Jul 31, 2017.

doi: $10.21037 /$ jtd.2017.10.37

View this article at: http://dx.doi.org/10.21037/jtd.2017.10.37

The thoracotomy approach was shown to be an effective surgical access in terms of preventing effusion recurrence and the need for repeat surgery (1). However, cardiac herniation remains a potential complication after extensive pericardial excision (2,3). A 54-year old female with a symptomatic chronic pericardial effusion significantly increasing in size over months (Figure 1) with the background of anti-cyclic citrullinated peptide (anti-CCP) antibody positive rheumatoid arthritis underwent surgical



Figure 1 Chronic pericardial effusion with the background of anti-cyclic citrullinated peptide (anti-CCP) antibody positive rheumatoid arthritis on the MRI-scan. pericardial window procedure through left anterior minithoracotomy. A large area of anterolateral pericardium was excised creating a generous $(13 \mathrm{~cm} \times 6 \mathrm{~cm})$ pericardial window with the view to achieving appropriate long-term drainage. In order to prevent potential heart herniation through the pericardial window an 8 -mm wide pericardial stripe was attached to both edges of the window using two single 5-0 sutures (Figure 2). Not only can this simple surgical technique prevent cardiac herniation but also avoids



Figure 2 An 8-mm wide pericardial stripe is attached to both edges of the window using two single 5-0 sutures preventing cardiac herniation on one side and obstruction of the left artery descending on the other side. 
potential obstruction of the left artery descending that can occur when a simple suture connecting both pericardial edges is used instead. Postoperatively the patient did not show any complications and has been doing well for more than 1 year of follow-up.

\section{Acknowledgements}

None.

\section{Footnote}

Conflicts of Interest: The authors have no conflicts of interest to declare.

\section{References}

1. Langdon SE, Seery K, Kulik A. Contemporary outcomes after pericardial window surgery: impact of operative technique. J Cardiothorac Surg 2016;11:73.

2. Casalduero J, García-Mangas P, Palacios V. Cardiac herniation through pericardial window. Med Intensiva 2006;30:90.

3. Rothschild PA, Tarver RD, Boyko OB, et al. MR diagnosis of herniation of the left ventricle through a pericardial window. Comput Radiol 1987;11:15-20.
Cite this article as: Sabashnikov A, Kuhn-Régnier F, Zeriouh M, Choi YH, Madershahian N, Wahlers T. Prevention of cardiac herniation and left artery descending obstruction in cases of extensive surgical pericardial window procedure. J Thorac Dis 2017;9(11):4597-4598. doi: 10.21037/ jtd.2017.10.37 